\title{
EFFECTS OF BLUE LIGHT AND PACLOBUTRAZOL ON SEED GERMINATION, VEGETATIVE GROWTH AND YIELD OF BLACK RICE (Oryza sativa L. 'Cempo Ireng')
}

\author{
KUMALA DEWI $^{1 *}$, RIZKIKA ZAKKA AGUSTINA ${ }^{2}$ and FARIDA NURMALIKA ${ }^{2}$ \\ ${ }^{1}$ Faculty of Biology, Universitas Gadjah Mada, Yogyakarta 55281, Indonesia \\ ${ }^{2}$ Alumni of Faculty of Biology, Universitas Gadjah Mada, Yogyakarta 55281, Indonesia
}

Received: 8 April 2015/Accepted: 8 August 2016

\begin{abstract}
Black rice (Oryza sativa L. "Cempo Ireng”) is one of local rice varieties in Sleman Regency, Yogyakarta. The black color is caused by high anthocyanin content which is important source of antioxidant. The cultivation of black rice is still limited due to its tall phenotype, long vegetative stage and low productivity compared to white rice. Paclobutrazol is a growth retardant causing dwarfing in several crop plants and reducing lodging. Blue light can improve plant quality. This research was aimed to evaluate the effect of blue light and paclobutrazol on seed germination, vegetative growth and yield of black rice. The results showed that the average of seed germination as well as the activity of $\alpha$-amylase of seeds subjected to blue light were lower compared to those subjected to sunlight; however, paclobutrazol concentrations did not affect seed germination percentage. The height of rice plants treated with paclobutrazol decreased in accordance with the increase of paclobutrazol concentration. Chlorophyll content and tiller numbers increased by paclobutrazol treatment of $12.5 \mathrm{ppm}$. Nitrate reductase activity was higher in rice seedlings subjected to blue light compared to those subjected to sunlight. Iron ( Fe) content of rice plants treated with 25 or $50 \mathrm{ppm}$ paclobutrazol increased compared to control. It was concluded that paclobutrazol application of $12.5 \mathrm{ppm}$ already reduced plant height. The higher concentration of paclobutrazol applied the greater reduction on plant height was observed. Blue light treatment applied during black rice seed germination slightly reduced germination percentage and $\alpha$-amylase activity in the germinated seeds. However, blue light treatment combined with paclobutrazol application during black rice seed germination increased chlorophyll content, tiller numbers and Fe content in black rice grain.
\end{abstract}

Keywords: $\alpha$-amylase activity, anthocyanin, blue light, Fe content, paclobutrazol

\section{INTRODUCTION}

Rice is among staple food having many varieties. Besides white rice, there are brown rice, red rice and black rice varieties. The price of black rice is relatively more expensive than that of white rice. The higher price of black rice may have been caused by the increasing awareness of people to consume black rice which contains more vitamins, minerals and anthocyanin. Anthocyanin content in black rice was reported to be beneficial for human health as it can lower cholesterol level in the blood and reduce the risk of arteriosclerosis

\footnotetext{
* Corresponding author: kumala.dewi@ugm.ac.id

** This paper was presented in the $2^{\text {nd }}$ International Conference on Advances in Plant Sciences (ICAPS 2014) organized by V Sivaram Research Foundation and Universiti Teknologi MARA on 18 - 22 November 2014 in Kuching, Sarawak, Malaysia
}

(Ling et al. 2001). However, not many farmers choose to cultivate black rice because the vegetative phase of black rice is longer than that of white rice. In addition, birds as well as the rice earhead bug (Leptocorisa oratorius) like to feed on developing black rice caryopsis which cause severe loss in black rice yield. The phenotype of black rice is also taller compared to other rice hybrids causing problems in cultivation.

Paclobutrazol is a synthetic growth inhibitor that acts by blocking gibberellin biosynthesis in plant (Rademacher 2000) resulting to semidwarf or dwarf plants. Semidwarf character is one of important traits, as semidwarf plants are lodging resistance. The productivity of semidwarf plant also increased because assimilates translocation is more directed to develop seeds rather than to develop new leaves or buds (Evans 1993). Dwarfisme can be due to either deficiency in 
gibberellin biosynthesis or inhibition in gibberellin signalling (Spielmeyer et al. 2004). Application of paclobutrazol to create semidwarf plants was reported in rice subspecies "Keng", in which $22.5 \mathrm{~g} / \mathrm{mL}$ paclobutrazol reduced stem height and increased tiller numbers (Minzi 1993). It was also reported that application of paclobutrazol effectively reduced vegetative growth of rice plants and increased chlorophyll content. Rice seedlings treated with paclobutrazol allocated more photosynthates for seed development compared to control plants or those plants treated with gibberellin (Yim et al. 1997). In corn (Zea mays L.) under drought stress, application of $50 \mathrm{ppm}$ paclobutrazol increased yield and average weight of 1,000 seeds (Bayat \& Sepehri 2012).

Blue light is light spectrum having wave length of 320 - $490 \mathrm{~nm}$ (Dougher \& Bugbee 2004). Receptor of blue light is known as Blue Light Absorbing Photoreceptor (BAP) (Meijer 1968; Gaba \& Black 1979; Thomas 1981). Plants respond differently to blue light irradiation (Dougher \& Bugbee 2004). According to Guerra et al. (1985), wheat plants subjected to blue light showed a decrease in the activity of enzymes regulating lignification which promoted shoot elongation. In Phaseolus vulgaris, blue light increased cell expansion (Van Volkenburgh et al. 1990). In rice seedlings, respiratory activity of plants subjected to blue light increased to about 1.5 folds compared to those treated with white light. This was due to an increase in the activity of piruvat kinase and malat dehidrogenase enzymes regulating cell respiration which caused the increase of ATP production and blue light irradiation (Yu \& Pan 1996). In addition, activity of nitrate reductase, nitrite reductase, glutamate synthetase and glutamin synthetase were higher in rice seedlings subjected to blue light for $5-7$ days compared to those subjected to white light. However, if the seedlings were subjected to blue light for more than 10 days, the activity of those enzymes declined (Deng et al. 2000). Nitrate reductase is an enzyme that catalyzes reduction of nitrate to nitrite. Several studies indicated that the level of nitrate reductase in plant tissues is altered by exogenous application of phytohormones (MacKintosh 1998). The activity of nitrate reductase in rice increases with the application of cytokinin and 2-chloro ethyl trimethyl ammonium chloride, which are gibberellins biosynthesis inhibitor (Hemalatha $2002)$. Glutamine 2-oxoglutarate aminotransferase (glutamate synthase, GOGAT) and glutamine synthetase (GS) are the key enzymes in primary assimilation and reassimilation of nitrogen in plants. These enzymes catalyze coupled reactions known as the GS/GOGAT cycle, through which inorganic nitrogen is transformed into organic nitrogen $(\mathrm{Lu}$ etal.2011).

Improving iron content and its bioavailability in rice have been applied to alleviate or to solve micronutrient deficiency in human. Iron content in black rice is higher than that in other rice types (Meng et al. 2005). Several methods to improve iron content and its bioavailability in rice seeds have been conducted, such as breeding, genetic engineering, biochemical and physical approaches. The objective of this research was to evaluate the effect of blue light and paclobutrazol on growth, $\alpha$-amylase activity, nitrate reductase, iron content and yield in black rice.

\section{MATERIALS AND METHODS}

'Cempo Ireng' black rice seeds were selected and soaked in aquadest for 24 hours. Plastic trays of $18 \times 24 \mathrm{~cm}$ were prepared and filled with a mixture of top soil and compost $(3: 1=\mathrm{v} / \mathrm{v})$ as growth media. One hundred seeds were spread and germinated in each plastic tray. The media was then wetted with either tap water (control) or paclobutrazol solution of $12.5,25,50$ or 100 ppm. Seeds were then placed under natural light in the green house or in a growth chamber installed with blue LED (Light Emitting Diode). The average daily temperature and relative humidity inside the green house were $30{ }^{\circ} \mathrm{C}$ and $70 \%$, respectively. The seeds were subjected to blue light for 12 hours per day from 06:00 am to 06:00 pm until the seedlings were 3 weeks old. The photosynthesis photon flux level for natural light and blue light was $300 \mu \mathrm{mol} / \mathrm{m}^{2} / \mathrm{s}$ and 30 $\mu \mathrm{mol} / \mathrm{m}^{2} / \mathrm{s}$, respectively (LI-250A Light Meter, LI-COR $\left.{ }^{\circledR} U S A\right)$. For each combination treatment, five replications were made. Germination percentage was determined on day 7. At the same time, the $\alpha$-amylase activity in germinated seeds was determined in $10 \mathrm{mg}$ whole grain samples. The CERALPHA kit (Megazyme International Ireland Ltd) was used based on the 
manufacturer's protocol and with appropriate dilutions. Data were expressed in CU (ceralpha unit) per g flour. At day 14, several parameters were determined such as seedling height, chlorophyll content and activity of nitrate reductase. Chlorophyll content was determined spectrophotometrically according to Harborne (1973). Nitrate reductase activity was determined spectrophotometrically according to Hartiko et al. (1984). At day 21, seedlings treated with paclobutrazol showing dwarf phenotype were selected and then transplanted in plastic pots containing a mixture of top soil and compost $(3: 1$ $=\mathrm{v} / \mathrm{v})$. In each plastic pot, two seedlings were planted. Each treatment combination had five replications. All plants were watered regularly and organic liquid fertilizer was applied every two weeks. At week twelve, plant height was measured and tiller numbers were determined. The plants were harvested at week 20, followed by the determination of 100 harvested seeds weight and iron content. The iron content was determined using Atomic Absorption Spectrometry (AAS). One gram of black rice grain (two samples per treatment) were weighed and placed in a furnace at $500-600{ }^{\circ} \mathrm{C}$ for 4 hours. Samples were then cooled and subjected to wet digestion with $10 \mathrm{~mL}$ of $\mathrm{HCl} 20 \%$. Samples were filtered with Whatman No.3 filter paper and placed in $50 \mathrm{~mL}$ volumetric flask and filled up to the mark with doubledistilled water. Total Fe content of the grain samples were determined using Perkin Elmer 3110 AAS (Welz \& Sperling 2007). Data were analyzed using ANOVA and DMRT (Duncan's Multiple Range Test) to determine the significant difference between treatments.

\section{RESULTS AND DISCUSSION}

The average of seed germination percentage of black rice seeds treated with paclobutrazol and blue light is presented in Figure 1. Under sunlight, germination percentage of black rice seeds was $100 \%$ for control seeds. Germination percentage of seeds treated with $12.5 \mathrm{ppm}$ paclobutrazol was $98 \%$. Germination percentage of seeds treated with 25,50 or 100 ppm reached $90 \%$. Subjected to blue light, germination percentage of black rice seeds was $80-85 \%$ and there were no significant differences between control seeds and seeds treated with paclobutrazol. This result indicated that primary dormancy of black rice seeds was possibly influenced by blue light. Seed germination can be influenced by dormancy level and light quality. In arabidopsis, white light and red light tend to increase seed germination, while in cerealia, such as barley and wheat, white light and blue light maintain dormancy level in the seeds (Gubler et al. 2008). In barley, blue light increased the expression of genes encoding enzymes that catalyze the biosynthesis of abscisic acid. As a consequence, the abscisic acid content was high, but on the other hand, the expression of genes encoding enzymes that catalyze gibberellins biosynthesis decreased (Gubler et al. 2008). Inhibition in barley seed germination subjected to blue light was due to an increase in abscisic acid level to about 3.5 folds compared to control (Hoang et al. 2013).

The increase in abscisic acid level was a result of an increase in the expression of genes encoding of the enzyme that catalyzed abscisic acid biosynthesis namely HvNCED1 and

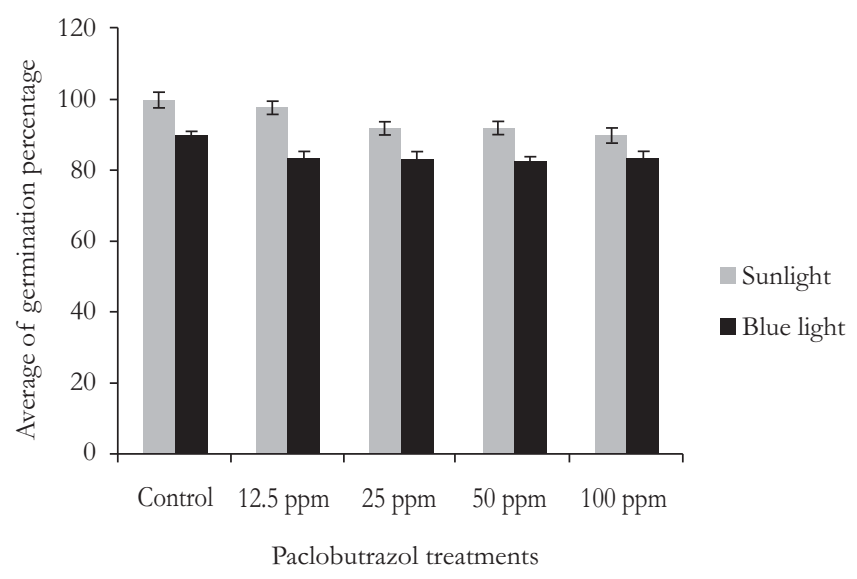

Figure 1 Effect of sunlight and blue light against paclobutrazol on average of germination percentage \pm SE of black rice 'Cempo Ireng' $(\mathrm{n}=5)$ 
$H v N C E D 2$, as well as an increase in the embryo sensitivity to abscisic acid. Blue light also decreased the expression of gene encoding of an enzyme that catalyzed gibberellin biosynthesis ( $H v G A 30 \times 2)$, but increased the expression of gene encoding of an enzyme that catabolized gibberellin. In wheat, seed germination inhibition subjected to blue light can be prevented by the presence of methyl jasmonate or nitrite oxide. It was also proven that methyl jasmonate application reduced the level of abscisic acid, and it was due to a decrease in the expression of gene encoding of an enzyme that catalyzed abscisic acid biosynthesis (TaNCED1) and a reduction the expression of $\mathrm{Ta} A B A^{\prime} \mathrm{OH}-1$ which encoded an enzyme that catalyzed degradation of abscisic acid (Jacobsen et al. 2013). The mechanism by which seed germination in black rice was inhibited by blue light was probably due to an increase in abscisic acid level and reduction in gibberellin biosynthesis. This assumption warrants further examination.

\section{$\alpha$-amylase Activity}

Germination processes in cereals are also determined by the activity of enzymes that degrade carbohydrate in the endosperm to its sugar component. $\alpha$-amylase is one of enzymes that plays a role during cereals seed germination. In this experiment, the activity of $\alpha$-amylase was determined according to procedure mentioned in CERALPHA kit (Megazyme International Ireland Ltd).

$\alpha$-amylase activity in germinated rice grains without paclobutrazol application was slightly lower in grains subjected to blue light compared to those subjected to sunlight (Table 1). This finding is related to the average of germination percentage which also decreased in black rice seeds subjected to blue light. In barley, blue light increased abscisic acid level and significantly increased embryo sensitivity to abscisic acid (Hoang et al. 2014; Barrero et al. 2014). The result of this study indicated that a slight inhibition in seed germination of black rice seeds subjected to blue light was due to either higher level of abscisic acid in the seeds or the sensitivity of embryo to abscisic acid. It was known that abscisic acid repressed the activity and signalling of gibberellin that induced $\alpha$-amylase during seed germination in cereals (Ishibashi et al. 2012). In arabidopsis, the level of endogenous abscisic acid increased about two folds as compared to control by application of uniconazol (Saito et al. 2008). In this study, interaction between paclobutrazol and blue light on $\alpha$-amylase activity was evaluated in the germinated black rice seeds. The activity of $\alpha$ amylase in black rice seeds treated with $12.5 \mathrm{ppm}$ paclobutrazol and germinated under sunlight decreased around $13 \%$ compared to control. This could be due to lower level of gibberellin produced during seed germination which led to reduction in $\alpha$-amylase activity. Nevertheless, $\alpha$ amylase activity in black rice seeds treated with 25 to $100 \mathrm{ppm}$ paclobutrazol was relatively similar to control. These results were probably due to the feedback mechanism in which gibberellins biosynthesis was repressed by paclobutrazol. However, the expression of genes encoding of enzymes that catalyzed gibberellins biosynthesis was changed and it might also alter the expression of genes encoding $\alpha$-amylase and/or $\alpha$-amylase activity. Lenton et al. (1994) showed that paclobutrazol application in wheat caused a decrease in the endogenous gibberellin in the scutellum, but it did not influence the expression of $\alpha$-amylase mRNA. However, the decline in endogenous gibberellin in wheat endosperm was related with downregulation of $\alpha$-amylase mRNA. From that report, it was suggested that the initiation of $\alpha$-amylase gene expression in the

Table 1 Average \pm SE of $\alpha$-amylase activity in black rice treated with blue light and paclobutrazol $(\mathrm{n}=5)$

\begin{tabular}{lcc}
\hline \multirow{2}{*}{ Treatment } & \multicolumn{2}{c}{$\begin{array}{c}\alpha \text {-Amylase activity (Ceralpha Units/g) } \\
\text { subjected to }\end{array}$} \\
\cline { 2 - 3 } & \multicolumn{1}{c}{ Sunlight } & Blue light \\
\hline Paclobutrazol $0 \mathrm{ppm}$ & $204.00 \pm 10.29 \mathrm{~d}$ & $165.88 \pm 2.63 \mathrm{a}$ \\
Paclobutrazol $12.5 \mathrm{ppm}$ & $176.02 \pm 7.98 \mathrm{ab}$ & $196.47 \pm 6.37 \mathrm{bcd}$ \\
Paclobutrazol $25 \mathrm{ppm}$ & $201.96 \pm 11.53^{\mathrm{cd}}$ & $198.07 \pm 5.72 \mathrm{bcd}$ \\
Paclobutrazol $50 \mathrm{ppm}$ & $204.60 \pm 4.19 \mathrm{~d}$ & $193.54 \pm 7.15 \mathrm{bcd}$ \\
Paclobutrazol $100 \mathrm{ppm}$ & $197.51 \pm 6.67 \mathrm{bcd}$ & $178.71 \pm 5.14 \mathrm{abc}$ \\
\hline
\end{tabular}


scutellum did not depend on a new gibberellin. However, the expression of $\alpha$-amylase gene in the endosperm depended on gibberellin biosynthesis in the embryo. This suggestion is in accordance with the fact that germination still occurred in black rice seeds treated with 100 ppm paclobutrazol, which might be caused by sufficient gibberellin in the scutellum. Therefore, initiation of $\alpha$-amylase gene expression could also be carried out. It should be noted that there was still an inhibition on shoot growth of black rice seeds treated with paclobutrazol. This may be related to inhibition of new gibberellin biosynthesis in the shoot. In arabidopsis, application of uniconazole, which is also a gibberellins inhibitor, caused shoot stunting, but with enhanced elongation of the primary roots (Bidadi et al. 2009). In semidwarf rice (sd1) obtained from a mutation of the GA20ox-2 gene, the level of endogenous gibberellin was low, however, the normal height of the semidwarf rice is restored by exogenous application of GA (Ashikari et al.2002; Sasaki et al.2002). This gene is expressed mainly in stems and is an important regulatory step on the pathway to synthesize active GA (reviewed in Hedden 2003). Semidwarf rice was also obtained from suppression of OsGA200x1 gene which suggested to be involved in the regulation of shoot stature in rice (Oikawa $e t$ al. 2004). In addition, different alleles of the GAresponsive dwarf rice $(d 18)$ are associated with mutations in the $O s G A 30 \times 2$ gene that is also expressed highly in stems (Itoh et al. 2001).

The probability of phototropin involvement in the biosynthesis of gibberellin and activity of $\alpha$ amylase also warrant further evaluation. The activity of amylase in black rice seeds treated with paclobutrazol and subjected to blue light tend to increase compared to those of control. The endogenous gibberellin decreased rapidly in rice seedlings subjected to blue light, due to a decrease in expression of genes that involved in gibberellin biosynthesis (OsGA200x2 and OsGA200x4) and an increase in expression of genes encoding the enzyme that catabolized gibberellin (OsGA2ox4 and $O s G A 20 \times 7)$. In addition, analysis in blue light receptor mutants (cry 1a dan cry 1b) also showed that the mechanism of blue light in decreasing the biosynthesis of gibberellin was through an increase in the expression of genes that involved in gibberellin catabolism (Hirose et al. 2012). Commonly, there are several isozymes that catalyze the biosynthesis of gibberellins and it could be that some of those isozymes were upregulated as a feedback mechanism when the level of endogenous gibberellins was lowered by paclobutrazol treatment. The upregulation of some isozymes that involved in gibberellins biosynthesis may also influence the activity of $\alpha$ amylase. Mustard (Sinapis alba L.) seedlings experienced increase of $\beta$-amylase activity in the cotyledon after being subjected to continuous blue light for $42-96$ hours from sowing. After that, the $\beta$-amylase activity abruptly declined (Manga \& Sharma 1988). In this research, the $\alpha$ amylase activity was only determined in 3 days old germinated seeds. Further experiment is still required to observe the pattern of amylase activity until seedlings were established.

\section{Average of Plant Height and Tiller Numbers}

Application of paclobutrazol can cause semidwarf or dwarf phenotype and it depends on the concentration applied (Rademacher 2000). Paclobutrazol concentrations of $200 \mathrm{mg} / \mathrm{L}$ to $600 \mathrm{mg} / \mathrm{L}$ decreased gibberellin content in the leaves compared to that of control when applied to rice plant during (Syahputra et al. 2013). The average of plant height in black rice treated with blue light and paclobutrazol at seedling stage 3 weeks old and at heading date is presented in Figure 2 and Figure 3.

Paclobutrazol application reduced plant height (Fig. $2 \& 5$ ). The measurement that was carried out on 3 weeks old black rice seedlings showed that $12.5 \mathrm{ppm}$ paclobutrazol applied during seed germination stage caused plant height reduction to about $25 \%$ compared to control, both in seedlings subjected to blue light or sunlight. Greater concentration of paclobutrazol caused severe dwarfism. Seeds that still germinated under $100 \mathrm{ppm}$ paclobutrazol were so small and it was impossible to replant the seeds in bigger plastic pots. Thus, further growth evaluation only used seedlings treated with either control or $12.5,25$ or $50 \mathrm{ppm}$ paclobutrazol. This study showed that after black rice seedlings were being grown in open area for 12 weeks, those plants treated with $12.5 \mathrm{ppm}$ paclobutrazol with or without blue light during germination still experienced 16 $20 \%$ reduction in the average of plant height compared to control. Black rice plants that previously treated with either 25 or $50 \mathrm{ppm}$ 


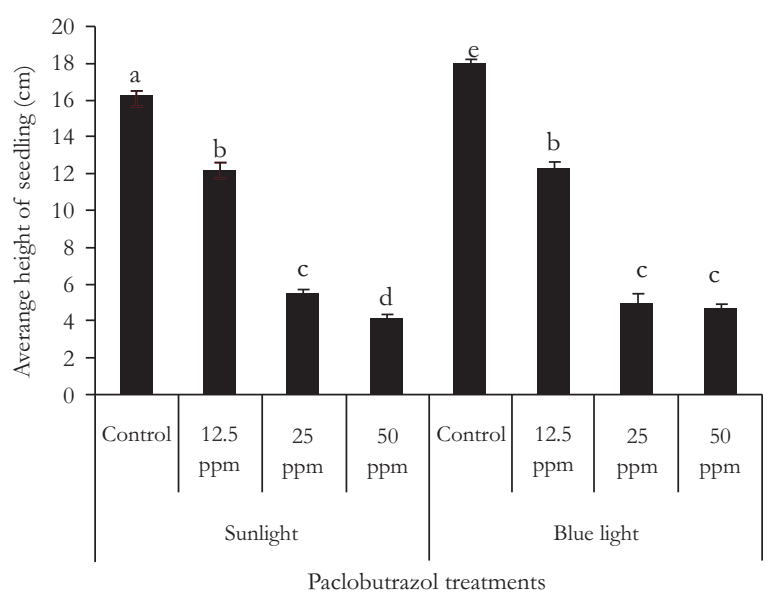

Figure 2 Average \pm SE height of seedlings treated with blue light and paclobutrazol $(\mathrm{n}=18)$

Notes: a - e: Bar charts having the same letters on top are not significantly different at $p<0.05$ based on DMRT (Duncan 1955)
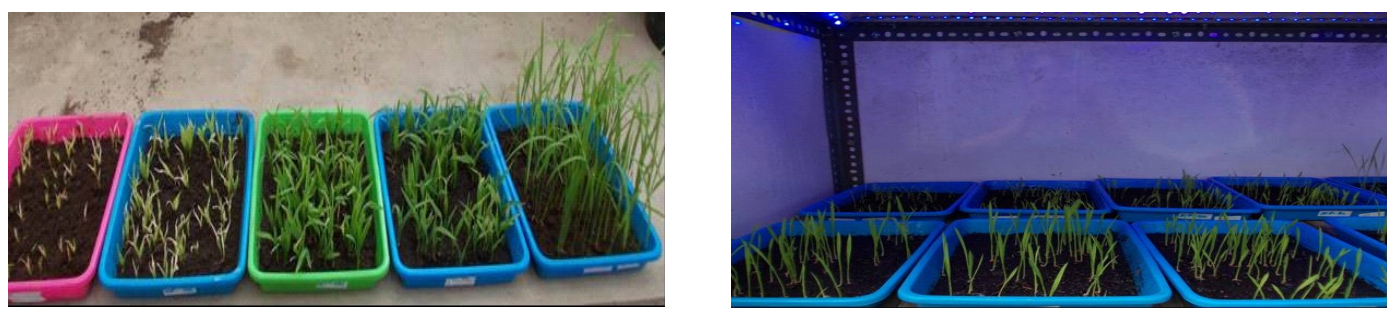

Figure 3 Growth performance of black rice seedlings grown under (a) sunlight and (b) blue light

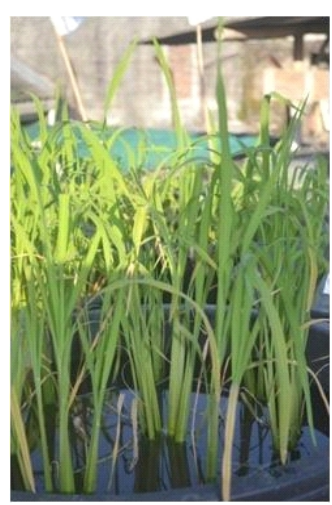

Control

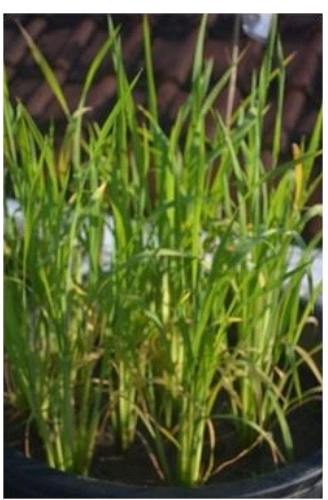

PBZ $12.5 \mathrm{ppm}$

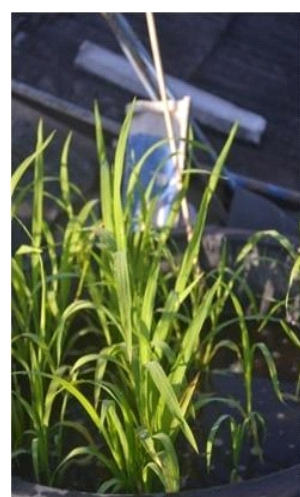

PBZ 25 ppm

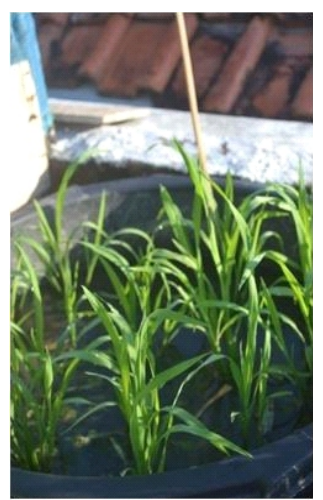

PBZ 50 ppm

Figure 4 Growth of black rice plant treated with paclobutrazol (PBZ) at 6 weeks after planting

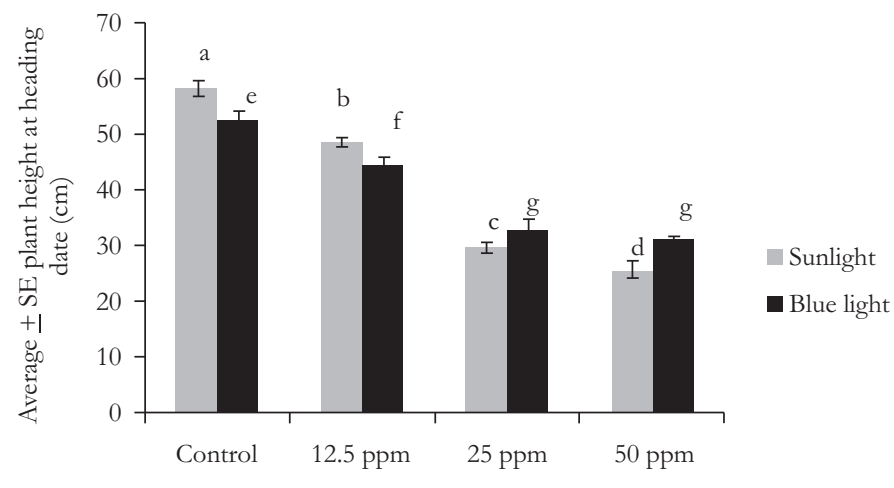

Figure 5 Average \pm SE plant height at heading date of black rice plant that previously treated with blue light and paclobutrazol $(\mathrm{n}=8)$

Notes: a - g: Bar charts having the same letters on top are not significantly different at $p<0.05$ based on DMRT (Duncan 1955) 
paclobutrazol still showed dwarfism (about 50\% reduction in plant height compared to control). This result indicated that paclobutrazol treatment during seed germination inhibited biosynthesis of gibberellin. However, tiller numbers in plants treated with $50 \mathrm{ppm}$ paclobutrazol increased significantly compared to control. The average of tiller numbers in black rice plants treated with paclobutrazol is presented in Figure 6.

Tiller numbers of black rice seeds subjected to blue light and 12.5 or $25 \mathrm{ppm}$ paclobutrazol increased compared to control (Fig. 6). In rice plant, auxin inhibited the biosynthesis of cytokinin and limited tiller growth (Liu et al. 2011). Application of paclobutrazol on mango plants (Mangifera indica L.) inhibited biosynthesis of gibberellin and auxin (Adil et al. 2011). Thus, it is possible that paclobutrazol treatment in black rice plants reduced biosynthesis of gibberellin as well as auxin. On the other hand, cytokinin biosynthesis increased causing the increase of tiller numbers. The mechanism of paclobutrazol in inducing tiller growth is interesting to be further evaluated. The dwarfism caused by paclobutrazol may also increase the resistance of plants towards waterlogging as well as pests and diseases attacks (Bridgemohan \& Bridgemohan 2014; Cohen et al. 1987).

\section{Chlorophyll Content}

Figure 7 shows the average of chlorophyll content in 3 months old black rice plant.

The average of total chlorophyll was higher on plants treated with paclobutrazol compared to control (Fig.7). This could be due to triazol applied during seed germination increased the biosynthesis of chlorophyll precursor, so that

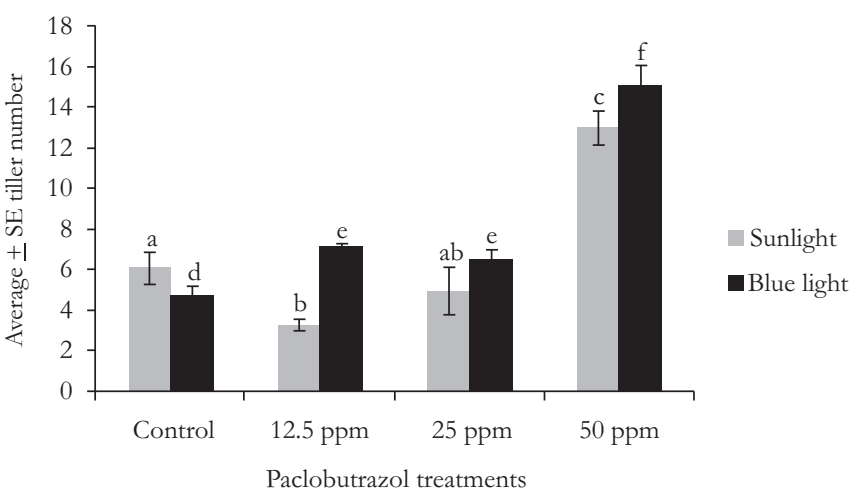

Figure 6 Average \pm SE tiller numbers of black rice plants subjected to paclobutrazol and blue light $(\mathrm{n}=8)$ Notes: $\mathrm{a}-\mathrm{f}$ : Bar charts having the same letters on top are not significantly different at $\mathrm{p}<0.05$ based on DMRT (Duncan 1955)

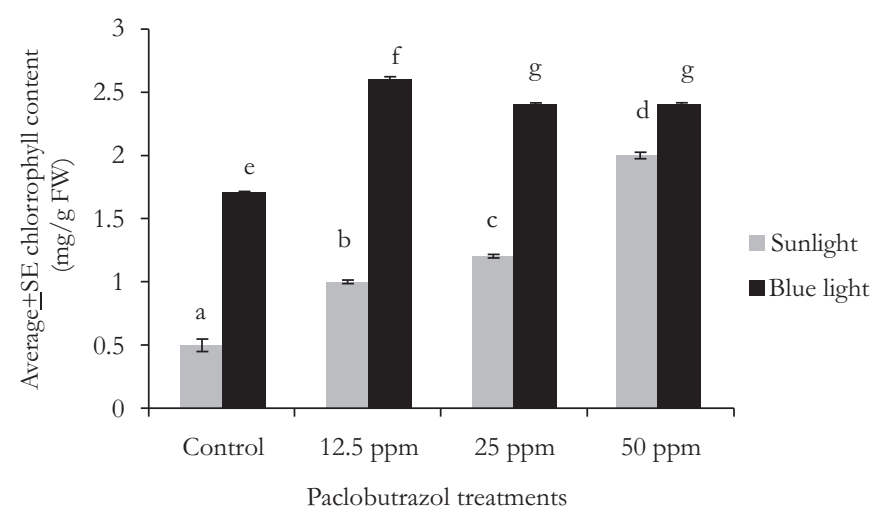

Figure 7 Average \pm SE total chlorophyll content of black rice plants subjected to paclobutrazol and blue light $(\mathrm{n}=5)$ Notes: $\mathrm{a}-\mathrm{g}$ : Bar charts having the same letters on top are not significantly different at $p<0.05$ based on DMRT (Duncan 1955) 
plants treated with paclobutrazol usually have higher chlorophyll content compared to control (Chaney 2005). Paclobutrazol application in Camelina sativa L. Crantz also increased chlorophyll content which led to greater rate in photosynthesis and higher yield (Kumar et al. 2012). Paclobutrazol also increased the activity of oxidative enzymes and enhanced plant resistence to water lodging in Ipomoea batatas L. (Lam) (Lin et al. 2008). The results of this experiment showed that black rice plants treated with either 25 or 50 ppm paclobutrazol have greener leaves compared to control; the leaves also experienced late senescence. This could be due to an increase in the activity of oxidative enzymes which prevented cell maturation. Slow senescence in leaves can prolong the phase of seed development and maturation. As a consequence, the yield can be increased, but the harvest time become late (Pan et al.2013).

\section{Activity of Nitrate Reductase}

Nitrate is a source of nitrogen for plant's cell. Nitrate is reduced to ammonium in roots which then be stored in the vacuole or transported to leaves. Reduction of nitrate to ammonium is catalyzed by nitrate reductase. The activity and transcript level of nitrate reductase in rice plant was suggested to be influenced by G-protein and protein kinase (Ali et al. 2007). The average of nitrate reductase activity in black rice plants treated with paclobutrazol and blue light is presented in Figure 8.

Activity of nitrate reductase increased in black rice plant treated with paclobutrazol and subjected to blue light during seed germination (Fig. 8). Similar finding was reported in arabidopsis, in which application of $\mathrm{GA}_{3}$ in light-grown Col-0 seedlings decreased nitrate reductase activity, but exogenous paclobutrazol enhanced nitrate reductase activity (Zhang et al. 2011). It was suggested that paclobutrazol application may also increase several oxidative enzymes (Lin et al. 2008). The increase in oxidative enzymes such as guaiacol peroxidase (POD), superoxide dismutases (SOD) and catalase (CAT) were related to an increase in nitrate reductase activity in ginger plant (Zingiber officinale Rosco) treated with $10^{-5} \mathrm{M}$ salycylic acid (Ghasemzadeh \& Jaafar 2013).

\section{Average Weight of 100 Seeds}

The average weight of 100 seeds in black rice plants treated with blue light and paclobutrazol of $25 \mathrm{ppm}$ is presented in Figure 9.

Paclobutrazol treatment did not influence the average weight of 100 seeds obtained from black rice plants subjected to sunlight (Fig. 9). However, in plants previously subjected to blue light, application of $25 \mathrm{ppm}$ paclobutrazol increased

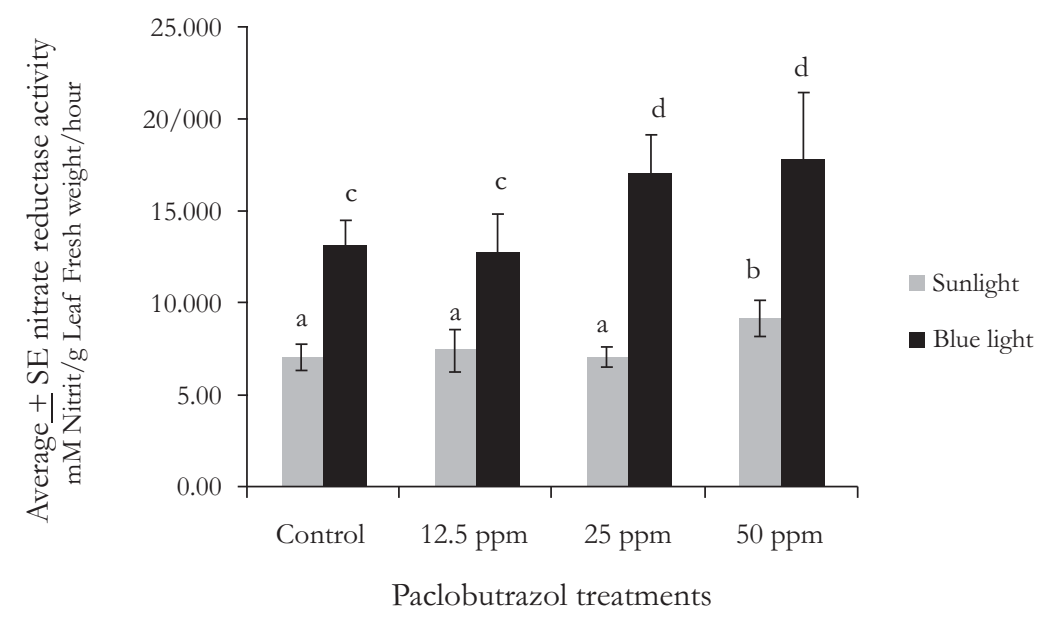

Figure 8 Average \pm SE nitrate reductase activity of black rice plants subjected to paclobutrazol and blue light $(\mathrm{n}=5)$ Notes: a - d: Bar charts having the same letters on top are not significantly different at $p<0.05$ based on DMRT (Duncan 1955) 


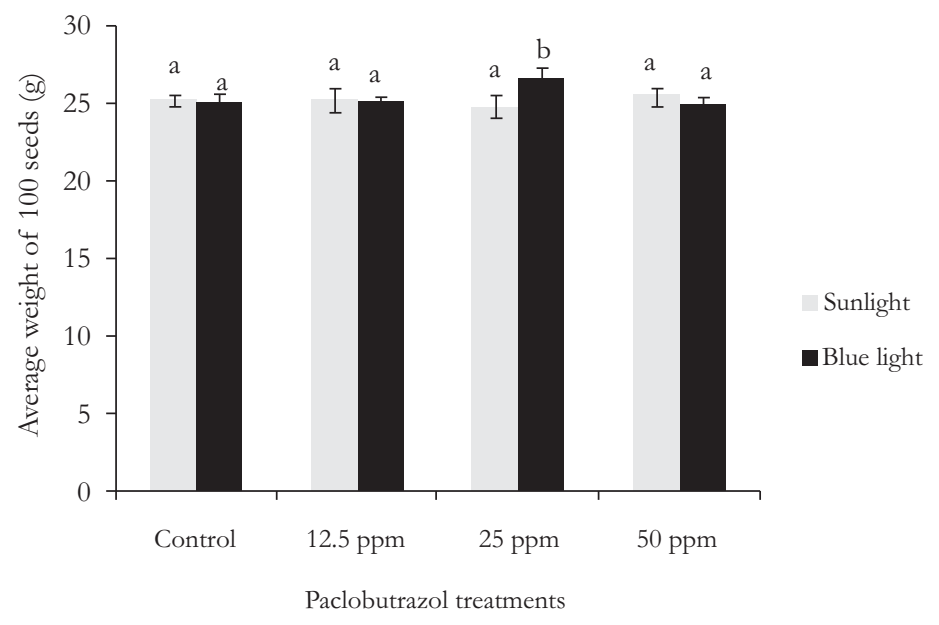

Figure 9 Average \pm SE weight of 100 seeds of black rice plants subjected to paclobutrazol and blue light $(\mathrm{n}=5)$ Notes: $a-b$ : Bar charts having the same letters on top are not significantly different at $p<0.05$ based on DMRT (Duncan 1955)

the average weight of 100 seeds compared to control or other treatments. This result was probably due to the fact that when plants were treated with blue light and $25 \mathrm{ppm}$ paclobutrazol, the leaves were greener and the chlorophyll content was higher compared to those of control. In terms of productivity, those plants treated with paclobutrazol of 25 or $50 \mathrm{ppm}$ had higher tiller numbers. Eventhough the weight of 100 seeds was similar to control, the total harvest of the plants treated with paclobutrazol was still relatively higher.

\section{Fe Content in the Seeds}

Fe content in the seeds was determined for plants treated with blue light and paclobutrazol (Fig. 10).
There was no significant effect of paclobutrazol on $\mathrm{Fe}$ content in black rice seeds harvested from plants without blue light treatment during seed germination (Fig. 10). On the other hand, when the seeds were germinated under blue light, the plants produced seeds containing higher Fe content. The increase of $\mathrm{Fe}$ content in potato tuber following treatment with paclobutrazol was also reported by Tekalign (2005). DeLaat et al. (2014) reported that ferritin is an essential iron homeostasis regulator in plant. Their studies showed that the expression of three ferritin gene in Phaseolus vulgaris L (PvFer1, PvFer2 and PvFer3) increased under iron excess and water deficit conditions. It has been reported that application of paclobutrazol could ameliorate abiotic stress condition, such as chilling or drought stress

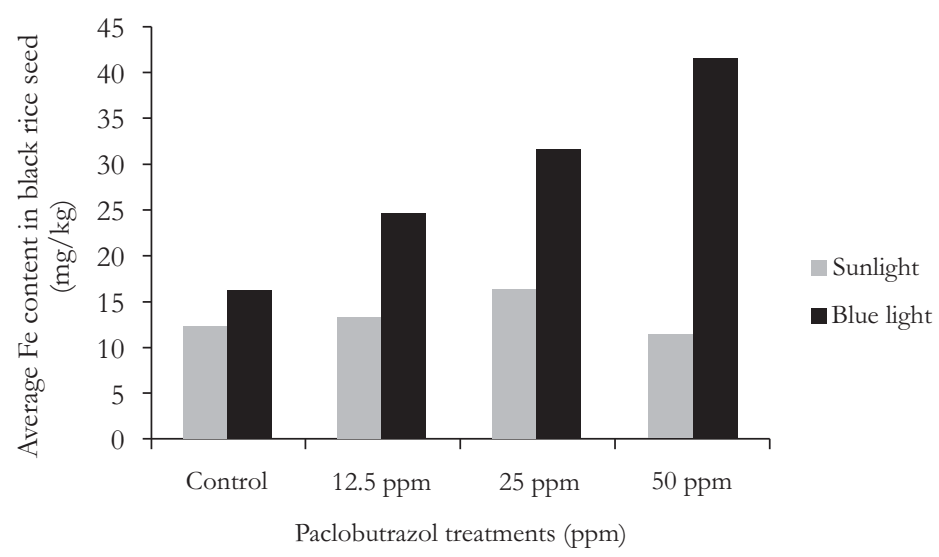

Figure 10 Average Fe content in black rice seed treated with blue light and paclobutrazol $(\mathrm{n}=2)$ 
through the ability of the plant to increase the activity of several antioxidant enzymes (Pan et al. 2013). In sweet potato, application of triazole increased the content of ascorbic acid, $\alpha$ tocopherol, riboflavin, anthocyanin, and xanthophylls and activities of ascorbate peroxidase, superoxide dismutase, and catalase activities (Sivakumar et al. 2010). Iron serves as a component of many vital enzymes such as cytochromes of the electron transport chain, thus required for a wide range of biological functions (Rout \& Sahoo 2015). It seems that there is an interaction between the increasing enzymatic activity triggered by triazole and iron uptake and accumulation in plant. The mechanism by which iron was accumulated in rice seeds of those plants treated with blue light and paclobutrazol is important to be further evaluated, since the bioavailability of iron in grains is important for human health. In addition, a simple and environmentally friendly technique for iron biofortification in grains is also important to be developed.

\section{CONCLUSIONS}

Blue light slightly reduced percentage of seed germination. Paclobutrazol application up to 100 ppm did not inhibit seed germination. Paclobutrazol reduced seedlings height. Tiller numbers, total chlorophyll content, nitrate reductase activity and $\mathrm{Fe}$ content in black rice increased in plants treated with blue light and 25 ppm paclobutrazol.

\section{ACKNOWLEDGEMENTS}

We wish to thank Ms. Dewi Kusumawati, and Mr. Martono for technical assistance and the "BOPTN FAKULTAS BIOLOGI UGM TAHUN ANGGARAN 2013" for financial support.

\section{REFERENCES}

Adil OS, Rahim A, Elamin OM, Bangerth FK. 2011. Effects of paclobutrazol (PBZ) on floral induction and associated hormonal and metabolic changes of biennialy bearing mango (Mangifera indica L.) cultivars during off year. ARPN J Ag \& Bio Sci 6(2):55-67.

Ali A, Sivakami S, Raghuram N. 2007. Regulation of activity and transcript levels of NR in rice (Oryza sativa): roles of protein kinase and G-proteins. Plant Sci 172:406-13.

Ashikari M, Ueguchi-Tanaka M, Sasaki A, Matsuoka M. 2002. Loss-of-function of a rice gibberellin biosynthetic gene, GA20 oxidase (GA20ox-2), led to the rice 'Green Revolution'. Breed Sci 52(2):14350 .

Barrero JM, Downie AB, Xu Q, Gubler F. 2014. A role for barley CRYPTOCHROME1 in light regulation of grain dormancy and germination. Plant Cell 26:1094-104.

Bayat S, Sepehri A. 2012. Paclobutrazol and salicylic acid application ameliorates the negative effect of water stress on growth and yield of maize plants. J Res Agric Sci 8(2):127-39.

Bidadi H, Yamaguchi, Asahina M, Satoh S. 2009. Effects of shoot-applied gibberellin/gibberellin-biosynthesis inhibitors on root growth and expression of gibberellins biosynthesis genes in Arabidopsis thaliana. Plant Root 4:4-11.

Bridgemohan P, Bridgemohan RSH. 2014. Evaluation of anti-lodging plant growth regulators on the growth and development of rice (Oryza sativa). J Cereals Oilseeds 5(3):12-6.

Chaney WR. 2005. Growth retardants: a promising tool for managing urban trees. Purdue Extension document FNR-252-W. Accessed on May 11, 2011 at: http://www.extension.purdue.edu/extmedia/FNR /FNR-252-W.pdf.

Cohen R, Yarden O, Katan J, Riov J, Lisker N. 1987. Paclobutrazol and other plant growth-retarding chemicals increase resistance of melon seedlings to fusarium wilt. Plant Pathol 36(4):558-64.

DeLaat DM, Colombo CA, Chiorato AF, Carbonel SAM. 2014. Induction of ferritin synthesis by water deficit and iron excess in common bean (Phaseolus vulgaris L.) Mol Biol Rep 41:1427-35.

Deng JM, Jin-Hua B, Rui-Chi P. 2000. Effects of light quality on the primary nitrogen assimilation of rice (Oryza sativa L.) seedling. Acta Bot Sin 42(3):234-8.

Dougher TA, Bugbee B. 2004. Long term blue light effects in the histology of lettuce and soybean leaves and stem. J Am Soc Horti Sci 129(4):467-72.

Duncan DB. 1955. Multiple range and multiple F test. Biometrics11:1-42.

Evans LT. 1993. Crop evolution, adaptation and yield. Cambridge University Press (UK). 500p.

Gaba V, Black M. 1983. Photocontrol of hypocotyl elongation in deetiolated Cucumis sativus L. rapid responses to blue light. J Photochem Photobiol 3:469-72. 
Ghasemzadeh A, Jaafar HZ E. 2013. Interactive effect of salicylic acid on some physiological features and antioxidant enzymes activity in ginger (Zingiber officinale Roscoe). Molecules 18:5965-79.

Gubler F, Hughes T, Waterhouse P, Jacobsen J. 2008. Regulation of dormancy in barley by blue light and after-ripening: effects on abscisic acid and gibberellin metabolism. Plant Physiol 147(2):886-96.

Guerra D, Anderson AJ, Salisbury FB. 1985. Reduced phenylalanine ammonia-lyase and tyrosine ammonia lyase activities and lignin synthesis in wheat grown under low pressure sodium lamps. Plant Physiol 78:126-30

Harborne JB 1973. Phytochemical methods: a guide to modern techniques of plant analysis. London (UK): Chapman \& Hall. p.204-11.

Hartiko H, del Rosario EJ, Carlos JT. 1984. Leaf and root nitrate reductase activities of coconut (Cocos nucifera L.) cultivars and hybrids. JIPI 3(6):227-35.

Hedden P. 2003. The genes of the Green Revolution. TIG 19:5-9.

Hemalatha S. 2002. Regulation of nitrate reductase activity in rice (Oryza sativa L.) by growth regulators. JCEA $3(3): 231-7$.

Hirose F, Inagaki N, Hanada A, Yamaguchi S, Kamiya Y, Miyao A, Hirochika H, Takano M. 2012. Cryptochrome and phytochrome cooperatively but independently reduce active gibberellin content in rice seedlings under light irradiation. Plant Cell Physiol 53(9): 1570-82.

Hoang H, Sechet HJ, Bailey C, Leymarie J, Corbineau F. 2014. Inhibition of germination of dormant barley (Hordeum vulgare L.) grains by blue light as related to oxygen and hormonal regulation. Plant Cell Environ 37(6):1393-403. doi: 10.1111/pce.12239.

Ishibashi Y, Tawaratsumida T, Kondo K, Kasa S, Sakamoto M, Aoki N, Zheng SH, Yuasa T, Iwaya-Inoue M. 2012. Reactive oxygen species are involved in gibberellin/abscisic acid signalling in barley aleurone cells. Plant Physiol 158:1705-14.

Itoh $\mathrm{H}$, Ueguchi-Tanaka M, Sentoku N, Kitano $\mathrm{H}$, Matsuoka M, Kobayashi M. 2001. Cloning and functional analysis of two gibberellin 3b-hydroxylase genes that are differently expressed during the growth of rice. Proc. Natl. Acad. Sci. USA 98:8909-14.

Jacobsen JV, Barrera JM, Hughes T, Julkowska M, Taylor JM, Xu Q, Gubler F. 2013. Roles for blue light, jasmonate and nitric oxide in the regulation of dormancy and germination in wheat greain (Triticum aestivum L.) Planta 238(1):121-38.

Kumar S, Ghatty S, Satyanarayana J, Guha A, Chaitanya BSK, Reddy A R. 2012. Paclobutrazol treatment as a potential strategy for higher seed and oil yield in field-grown Camelina sativa L. Crantz. BMC Res Notes 5:137.
Lin KH, Tsou CC, Hwang SY, Chen LFO, Lo HF. 2008. Paclobutrazol leads to enhanced antioxidative protection of sweet potato under flooding stress. Bot Stud 49:9-18.

Ling WH, Cheng QX, Ma J, Wang T. 2001. Red and black rice decreases artheroscherotic plaque formation aaaand increase antioxidant status in rabbits. J Nutr 131:1421-6.

LiuY, Xu J, Ding Y, Wang Q, Li G, Wang S. 2011. Auxin inhibits the outgrowth of tiller buds in rice (Oryza sativa L.) by downregulating OsIPTexpression and cytokinin biosynthesis in nodes. Aust J Crop Sci 5(2):169-74.

Lu Y, Luo F, Yang M, Li XH, Lian XM. 2011. Suppression of glutamate synthase genes significantly affects carbon and nitrogen metabolism in rice (Oryza sativa L.). Sci China Life Sci 54(7):651-63.

MacKintosh C. 1998. Regulation of plant nitrate assimilation from ecophysiology to grain proteins. New Phytol 139:153-9.

Manga VA, Sharma R. 1988. Blue light mediated regulation of $\beta$-amylase activity in mustard (Sinapis alba L.) cotyledons. Plant Cell Physiol 29(4):673-6.

Meijer G. 1968. Rapid inhibition of gherkin hypocotyls in blue light. Acta Bot Neerl 17:9-14.

Meng F, Wei Y, Yang X. 2005. Iron content and bioavailability in rice. J Trace Elem Med Biol 18(4):333-8.

Oikawa T, Koshioka M, Kojima K, Yoshida H, Kawata M. 2004. A role of OsGA20ox1, encoding an isoform of gibberellins 20-oxidase, for regulation of plant stature in rice. Plant Mol Biol 55:687-700.

Pan S, Rasul F, Li W, Tian H, Mo Z, Duan M, Tang X. 2013. Roles of plant growth regulators on yield, grain qualities and antioxidant enzyme activities in super hybrid rice (Oryza sativa L.). Rice 6:1-9. doi:10.1186/1939-8433-6-9.

Rademacher W. 2000. Growth retardants: effects on gibberellin biosynthesis and other metabolic pathways. Annu Rev Plant Physiol Plant Mol Biol 51:501-31.

Rout G, Sahoo S. 2015. Role of iron in plant growth and metabolism. Rev Agric Sci 3:1-24.

Saito S, Masanori O, Shoko S,Tetsuo K, Tomokazu K,Yuji K, Nobuhiro H, Yasushi T, Kanzo S, Eiji N, Masaharu M. 2008. A plant growth retardant, uniconazole, is a potent inhibitor of $\mathrm{ABA}$ catabolism in arabidopsis. Biosci Biotechnol Biochem 70(7):1731-39.

Sasaki A, Ashikari M, Ueguchi-Tanaka M, Itoh H, Nishimura A, Swapan D, Ishiyama K, Saito T, Kobayashi M, Khush GS, Kitano H, Matsuoka M. Green revolution: a mutant gibberellin-synthesis gene in rice. Nature 416(6882):701-2. 
Sivakumar T, Lakshmanan GMA, Murali PV, Panneerselvam R. 2010. Alteration of antioxidative metabolism induced by triazoles in sweet potato. $\mathrm{J}$ Exp Sci 1(3):10-3.

Spielmeyer W, Ellis MH, Robertson M, Ali S, Lenton JR, Chandler PM. 2004. Isolation of gibberellin metabolic pathway genes from barley and comparative mapping in barley, wheat and rice. Theor Appl Genet 109:847-55.

Syahputra BAS, Sinniah UR, Syed Rastan SO, Ismail MR. 2013. Changes in gibberellic acid $\left(\mathrm{GA}_{3}\right)$ content in Oryza sativa due to paclobutrazol treatment. J Food Pharm Sci 1:14-7.

Tekalign T. 2005. Growth and productivity of potato as influenced by cultivar and reproductive growth: I. Stomata conductance, rate of transpiration, net photosynthesis and dry matter production and allocation. Sci Hort 105:13-27.

Thomas B. 1981. Specific effects of blue light on plant growth and development. In: plants and the daylight spectrum. Smith H (Ed.). London (UK): Academic Press. p.443-59.

Yim KO, Kwon YW, Bayer DE. 1997. Growth responses and allocation of assimilates of rice seedling by paclobutrazol and gibberellin treatment. J Plant Growth Regul 16:35-41.

Yu R, Pan R. 1996. Effect of blue light on the respiration of rice (Oryza sativa) seedlings. Chinese J Rice Sci 10(3):159-62.

Van Volkenburgh E, Clealand RE, Watanabe M. 1990. Light-stimulated cell expansion in bean (Phaseolus vulgaris L.) leaves: quantity ad quality of light required. Planta 182(1):77-80.

Welz B, Sperling M. 2007. Atomic absorbtion spectrometry. Weinheim (DE): Wiley-VCH, Verlag Gmbh. DOI: 10.1002/9783527611690.fmatter.

Zhang Y, Liu Z, Liu R, Wang L, Bi Y. 2011. Gibberellin negatively regulate light induced nitrate reductase activity in arabidopsis seedlings. J Plant Physiol 168(8):2161-8. 